\title{
Long-term clinical effectiveness of a drug- coated balloon for in-stent restenosis in Femoropopliteal lesions
}

\author{
Kazunori Horie $^{1 *} \mathbb{D}$, Akiko Tanaka ${ }^{1}$, Kenji Suzuki ${ }^{2}$, Masataka Taguri ${ }^{3}$ and Naoto Inoue ${ }^{1}$
}

\begin{abstract}
Background: The short-term efficacy of paclitaxel-coated balloons (PCBs) has been established in femoropopliteal in-stent restenosis (ISR) lesions. The aim of this study was to compare 5-year clinical outcomes of patients with femoropopliteal ISR lesions undergoing percutaneous transluminal angioplasty (PTA) with and without PCB.

Methods: After 1:1 propensity score matching, we extracted 50 patients with femoropopliteal ISR lesions undergoing PTA with $(n=25)$ and without $(n=25)$ IN.PACT PCB (Medtronic, Minneapolis, MN) from 106 consecutive ISR patients treated in our hospital between 2009 and 2015. We compared the 5-year outcomes between PCB and non-PCB groups. The primary endpoint was the cumulative 5-year incidence of recurrent restenosis. All-cause mortality, target lesion revascularization (TLR) and unplanned major amputation were also assessed.
\end{abstract}

Results: The primary patency after PCB treatment at 5 years was significantly higher than the patency after non-PCB treatment (65.7\% vs. 18.7\%; hazard ratio [HR]: 6.11 ; $95 \%$ confidence intervals [CI]: $2.57-16.82 ; p<$ $0.001)$, as well as freedom from TLR (77.6\% vs. $53.8 \%$; HR: $3.55 ; 95 \% \mathrm{Cl}: 1.21-12.83 ; p=0.020)$. All-cause mortality and unplanned major amputation rates did not significantly differ between the two groups. The Cox proportional hazard multivariate analysis showed that PCB was independently associated with preventing recurrent restenosis (HR: 0.17; 95\% Cl: $0.06-0.41 ; p<0.001$ ).

Conclusions: At 5 years, patients with femoropopliteal ISR lesions undergoing PCB treatment showed significantly lower recurrent restenosis than those that underwent non-PCB treatment.

Evidence-based medicine: Level of Evidence: Level 2b, Non-randomized controlled cohort/follow-up study.

Keywords: Femoropopliteal segment, In-stent restenosis, Drug-coated balloon, Endovascular treatment

\section{Introduction}

Endovascular therapy (EVT) represents an established practice in the treatment of lower extremity peripheral arterial disease (PAD). The use of bare-nitinol stents (BNS) has led to good acute luminal gains in the past 2 decades; however, its primary patency has remained unsatisfactory (Schillinger et al., 2006; Soga et al., 2010; Iida

\footnotetext{
*Correspondence: horihori1015@gmail.com

'Department of Cardiovascular Medicine, Sendai Kousei Hospital, 4-15

Hirose-cho, Aoba-ku, Sendai, Miyagi 980-0873, Japan

Full list of author information is available at the end of the article
}

et al., 2014; Tosaka et al., 2012). Several paclitaxel-based devices have been developed to overcome the shortcomings of BNS (Gray et al., 2018; Laird et al., 2019). The new devices are associated with higher primary patency in de novo femoropopliteal lesions than plain balloon angioplasty and BNS, and the recent guideline recommends the primary EVT strategy to be deployed in complex femoropopliteal lesions (Aboyans et al., 2017).

The one-year efficacy of paclitaxel-coated balloons (PCB) has been proven also in treatment of femoropopliteal in-stent restenosis (ISR) after BNS implantation by

\section{Springer Open}

๑ The Author(s). 2021 Open Access This article is licensed under a Creative Commons Attribution 4.0 International License, which permits use, sharing, adaptation, distribution and reproduction in any medium or format, as long as you give appropriate credit to the original author(s) and the source, provide a link to the Creative Commons licence, and indicate if changes were made. The images or other third party material in this article are included in the article's Creative Commons licence, unless indicated otherwise in a credit line to the material. If material is not included in the article's Creative Commons licence and your intended use is not permitted by statutory regulation or exceeds the permitted use, you will need to obtain permission directly from the copyright holder. To view a copy of this licence, visit http://creativecommons.org/licenses/by/4.0/. 
randomized control trials (RCT) comparing to plain balloon angioplasty; therefore, PCB is one of the best solutions for ISR lesions (Krankenberg et al., 2015; Kinstner et al., 2016; Ott et al., 2017; Cassese et al., 2018). On the other hand, few studies have investigated the long-term patency after PCB treatment in ISR lesions of femoropopliteal segments, and the longest follow-up outcomes have been reported up to 3 years in the previous study (Grotti et al., 2016). In this study, we retrospectively compared the 5-year clinical outcomes of patients with femoropopliteal ISR undergoing percutaneous transluminal angioplasty (PTA) with and without PCB.

\section{Methods}

\section{Study population}

This retrospective, single-center, non-randomized study was performed to compare the immediate and 5-year outcomes of consecutive patients with femoropopliteal ISR lesions who underwent PTA using PCB (PCB group) and plain balloons (non-PCB group). Given that $\mathrm{PCB}$ has been commercially available since December 2018 in our country, we privately imported IN.PACT Pacific PCB (Medtronic, Minneapolis, MN) from 2008 to 2014 after approval by the institutional review board of our hospital. We analyzed 106 consecutive Asian patients (mean age: $72.1 \pm 8.7$ years; 68 males) with symptomatic PAD who underwent PTA for femoropopliteal ISR lesions at our hospital from 2009 to 2015 (Fig. 1). The key inclusion criteria were age $>50$ years, symptomatic PAD (Rutherford category 2 to 5), ISR $>70 \%$ at the stented site in femoropopliteal segments (Kinstner et al., 2016). We excluded patients with acute limb ischemia and/or short life expectancy, as in the previous studies (Cassese et al., 2018). The study protocol was developed in accordance with the Declaration of Helsinki and was

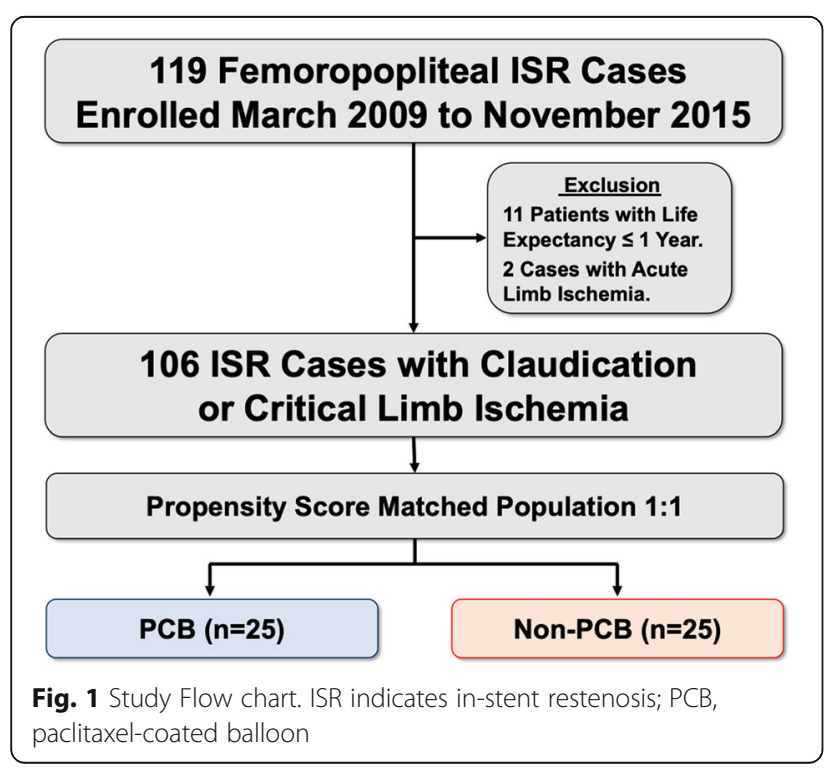

approved by the institutional review board of our hospital (approval no. 27-33). Informed consent was obtained from all patients.

\section{Procedures}

After local anesthesia with $2.0 \%$ xylocaine, a 6.0 - or 7.0 French guiding sheath was inserted via the ipsi- or contralateral common femoral artery. Unfractionated heparin (5000 IU) was injected initially from the sheath, with an additional $2000 \mathrm{IU}$ given intravenously every hour. In cases of in-stent occlusion, we initially attempted lumencrossing using 0.018- or 0.014-in. guidewires and microcatheters. If that was unsuccessful, the loop-wire technique was applied, using a 0.035 - or 0.018 -in. hydrophilic guidewire. If necessary, a retrograde approach was implemented, via either the popliteal or tibial arteries. At first, PTA was performed using plain balloons with nominal diameters same as the reference vessel diameter and with matched length to the lesion's, evaluated by visual estimation. Balloon dilatation was continued for at least 60 s. IN.PACT PCB was available in nominal diameters of 4 and $6 \mathrm{~mm}$ and nominal lengths of 60,80 , and $120 \mathrm{~mm}$ in our hospital. When the operators adjudicated that lesions could be covered by one or two PCB with the above sizes after successful balloon dilatation, IN.PACT PCB was dilated for at least $60 \mathrm{~s}$. Inflation time was based on the previous studies conducting $\mathrm{PCB}$ treatment (Krankenberg et al., 2015; Fanelli et al., 2014). PCB treatment was used after successful pre-dilatation; therefore, bail-out stenting was not performed in the PCB group.

\section{Definition and study endpoints}

All the lesions were characterized according to the Trans-Atlantic Inter-Society Consensus (TASC) II and Tosaka classification (Tosaka et al., 2012; Eur J Vasc Endovasc Surg, 2007). The immediate success of PTA was defined as achieving any residual stenosis of $<30 \%$ of the reference diameter, adjudicated by visual estimation. The Proposed Peripheral Arterial Calcium Scoring System was used to categorize the degree of native femoropopliteal lesion calcification (Rocha-Singh et al, 2014). All angiograms were independently evaluated by two experienced operators for baseline lesion morphology and procedural success. In outpatient follow-up, color Doppler ultrasound assessment was performed routinely every 12 months after EVT to evaluate the patency of the vessel. Restenosis was defined as a peak systolic velocity ratio over 2.4 on duplex ultrasonography, which was considered to indicate $>50 \%$ narrowing (Fanelli et al., 2014). The primary study endpoint was the recurrent restenosis within 5 years after PTA for ISR lesions. The secondary endpoints were all-cause mortality, target lesion revascularization (TLR) and unplanned major amputation within 5 years. 


\section{Statistical analysis}

In this study, a propensity score (PS) matching analysis was performed to adjust for the differences in baseline clinical characteristics between the two groups. The PS was estimated by a logistic regression model that included patient and lesion characteristics listed in Tables 1 and 2 as exploratory variables. The matching was performed using the nearest-neighbor method, with a caliper of 0.20. Categorical variables were presented as counts (percentages) and compared using the Chisquared or Fisher's exact tests. Continuous variables were expressed as mean \pm standard deviations and compared using the Student's t-test or the Mann-Whitney U test based on their distributions. In the matched population, the cumulative incidence of study endpoints was estimated using the Kaplan-Meier method. Hazard ratios (HRs) for recurrent restenosis, all-cause mortality, and TLR were compared between the PCB and non-PCB groups. To identify possible risk factors for recurrent restenosis, HRs for clinically selected patients, lesions, and procedural variables were estimated by univariate and multivariate Cox models. All statistical analyses were performed by two physicians using JMP version 14 (SAS Institute, Cary, NC). Values of $P<0.05$ were considered statistically significant.

\section{Results}

\section{Study population}

After PS matching, the final study population consisted of 25 matched patients in each group (Fig. 1).

\section{Baseline clinical characteristics}

Baseline patient and lesion characteristics before and after PS matching are displayed in Tables 1 and 2. Before PS matching, no significant differences in baseline clinical characteristics were observed between PCB and non-PCB groups, except for ISR patterns. After PS matching, baseline patient and lesion characteristics were well balanced between the two groups. Table 3 shows the comparison of procedural characteristics and results. Before and after PS matching, the balloon sizes and pressure before PCB dilatation were similar between the two groups. Since PCB was used after successful balloon pre-dilatation, the patients in the $\mathrm{PCB}$ group did not undergo bail-out stenting. The bail-out stenting was performed in 20 patients of the original population in the non-PCB group and the 12 patients had Tosaka III lesions (60.0\%). The PCB dilatation was successful in all patients of the PCB group. There was no significant difference in the rates of complications between the two groups.

Table 1 Baseline Clinical Characteristics

\begin{tabular}{|c|c|c|c|c|c|c|}
\hline \multirow[t]{2}{*}{ Variables } & \multicolumn{3}{|c|}{ Overall population } & \multicolumn{3}{|c|}{ Matched population } \\
\hline & PCB $(n=32)$ & Non-PCB $(n=74)$ & $p$ & PCB $(n=25)$ & Non-PCB $(n=25)$ & $p$ \\
\hline Age, years* & $70.8 \pm 7.2$ & $76.7 \pm 9.3$ & 0.320 & $71.9 \pm 7.5$ & $71.5 \pm 8.9$ & 0.864 \\
\hline Male sex* & $20(62.5)$ & $48(64.9)$ & 0.816 & $17(68.0)$ & $17(68.0)$ & 1.000 \\
\hline Body mass index, $\mathrm{kg} / \mathrm{m}^{2 *}$ & $23.8 \pm 3.7$ & $23.3 \pm 3.5$ & 0.531 & $23.4 \pm 3.7$ & $23.6 \pm 2.4$ & 0.770 \\
\hline Hypertension* & $31(96.9)$ & $64(86.5)$ & 0.167 & $24(96.0)$ & $25(100.0)$ & 1.00 \\
\hline Diabetes mellitus* & $26(81.3)$ & $49(66.2)$ & 0.163 & $19(76.0)$ & $17(68.0)$ & 0.754 \\
\hline Dyslipidemia* & $15(46.9)$ & $37(50.0)$ & 0.768 & $11(44.0)$ & $13(52.0)$ & 0.571 \\
\hline Current smoker* & $8(25.0)$ & $15(20.3)$ & 0.614 & $5(20.0)$ & $5(20.0)$ & 1.000 \\
\hline Chronic kidney disease* & $11(34.4)$ & $32(43.2)$ & 0.391 & $9(36.0)$ & $7(28.0)$ & 0.762 \\
\hline Hemodialysis* & $2(6.3)$ & $11(14.9)$ & 0.336 & $2(8.0)$ & $2(8.0)$ & 1.000 \\
\hline Rutherford class* & & & 0.067 & & & 1.000 \\
\hline $2 / 3$ & $31(96.9)$ & $62(83.8)$ & & $24(96.0)$ & $25(100.0)$ & \\
\hline 4 & $1(3.1)$ & $7(9.5)$ & & $1(4.0)$ & $0(0.0)$ & \\
\hline 5 & $0(0.0)$ & $5(6.8)$ & & $0(0.0)$ & $0(0.0)$ & \\
\hline Ankle brachial index & $0.63 \pm 0.12$ & $0.60 \pm 0.15$ & 0.375 & $0.62 \pm 0.13$ & $0.61 \pm 0.11$ & 0.792 \\
\hline \multicolumn{7}{|c|}{ Medication at treatment of ISR } \\
\hline Aspirin & $29(90.6)$ & $67(90.5)$ & 1.000 & $22(88.0)$ & $24(96.0)$ & 0.609 \\
\hline P2Y12 antagonist & $21(65.6)$ & $52(70.3)$ & 0.637 & $16(64.0)$ & $13(52.0)$ & 0.567 \\
\hline Cilostazol & $15(46.9)$ & $30(40.5)$ & 0.546 & $13(52.0)$ & $13(52.0)$ & 1.000 \\
\hline Oral anticoagulant & $2(6.3)$ & $14(18.9)$ & 0.140 & $2(8.0)$ & $5(20.0)$ & 0.417 \\
\hline
\end{tabular}

Categorical variables are expressed as number and percentage. Continuous variables are indicated as mean \pm SD ISR indicates in-stent restenosis, $P C B$ paclitaxel-coated balloon

*Variables included in the multivariable analysis to estimate propensity score 
Table 2 Baseline Lesion Characteristics

\begin{tabular}{|c|c|c|c|c|c|c|}
\hline \multirow[t]{2}{*}{ Variables } & \multicolumn{3}{|c|}{ Overall population } & \multicolumn{3}{|c|}{ Matched population } \\
\hline & PCB $(n=32)$ & Non-PCB $(n=74)$ & $p$ & PCB $(n=25)$ & Non-PCB $(n=25)$ & $p$ \\
\hline \multicolumn{7}{|l|}{ Target lesion } \\
\hline Superficial femoral artery & $32(100.0)$ & $74(100.0)$ & 1.000 & $25(100.0)$ & $25(100.0)$ & 1.000 \\
\hline Involving popliteal artery & $4(12.5)$ & $19(25.7)$ & 0.199 & $4(16.0)$ & $7(28.0)$ & 0.496 \\
\hline Reference vessel diameter, \% & $5.65 \pm 0.40$ & $5.54 \pm 0.47$ & 0.282 & $5.61 \pm 0.37$ & $5.50 \pm 0.49$ & 0.367 \\
\hline Lesion length of native disease, \% & $223.4 \pm 68.4$ & $200.9 \pm 81.4$ & 0.173 & $222.0 \pm 73.5$ & $209.6 \pm 78.4$ & 0.567 \\
\hline Total occlusion of native disease, $\%$ & $27(84.4)$ & $55(74.3)$ & 0.318 & $20(80.0)$ & $21(84.0)$ & 1.000 \\
\hline TASC II classification of native disease & & & 0.177 & & & 0.217 \\
\hline$A / B$ & $4(12.5)$ & $21(18.4)$ & & $3(12.0)$ & $6(24.0)$ & \\
\hline C & $6(18.8)$ & $15(20.3)$ & & $5(20.0)$ & $5(20.0)$ & \\
\hline $\mathrm{D}$ & $22(68.7)$ & $38(51.3)$ & & $17(68.0)$ & $14(56.0)$ & \\
\hline PACSS classification of native disease & & & 0.937 & & & 0.702 \\
\hline $0-3$ & $27(84.4)$ & $64(86.5)$ & & $20(80.0)$ & $22(88.0)$ & \\
\hline 4 & $5(15.6)$ & $10(13.5)$ & & $5(20.0)$ & $3(12.0)$ & \\
\hline Types of ISR-related stents & & & 1.000 & & & 1.000 \\
\hline Bare-nitinol stent & $30(93.7)$ & $69(93.2)$ & & $24(96.0)$ & $25(100.0)$ & \\
\hline SMART'M & $10(31.3)$ & $21(28.4)$ & & $7(28.0)$ & $9(36.0)$ & \\
\hline Luminexx $^{\mathrm{TM}}$ & $15(46.9)$ & $33(44.6)$ & & $14(56.0)$ & $13(52.0)$ & \\
\hline Zilver $518^{\mathrm{TM}}$ & $1(3.1)$ & $3(4.1)$ & & $1(4.0)$ & $0(0.0)$ & \\
\hline Misago $^{\mathrm{TM}}$ & $4(12.5)$ & $11(14.9)$ & & $2(8.0)$ & $2(8.0)$ & \\
\hline LIFE STENTTM & $0(0.0)$ & $1(1.4)$ & & $0(0.0)$ & $1(4.0)$ & \\
\hline Drug-coated stent (Zilver PTX'MM) & $2(6.3)$ & $5(6.8)$ & & $1(4.0)$ & $0(0.0)$ & \\
\hline ISR pattern* & & & $<0.001$ & & & 0.581 \\
\hline Focal $(\leq 50 \mathrm{~mm})$ & $2(6.3)$ & $25(33.8)$ & & $2(8.0)$ & $2(8.0)$ & \\
\hline Diffuse (> $50 \mathrm{~mm})$ & $24(75.0)$ & $22(29.7)$ & & $19(76.0)$ & $16(64.0)$ & \\
\hline Occlusion & $6(18.7)$ & $27(36.5)$ & & $4(16.0)$ & $7(28.0)$ & \\
\hline ISR length* & $120.3 \pm 59.3$ & $131.1 \pm 95.6$ & 0.555 & $126.0 \pm 57.4$ & $134.4 \pm 71.4$ & 0.649 \\
\hline Distal run-off vessel & & & 0.378 & & & 1.000 \\
\hline $2 / 3$ & $23(71.9)$ & $45(60.8)$ & & $17(68.0)$ & $18(72.0)$ & \\
\hline $0 / 1$ & $9(28.1)$ & $29(39.2)$ & & $8(32.0)$ & $7(28.0)$ & \\
\hline Stent fracture classification & & & 0.582 & & & 1.000 \\
\hline $0 / 1 / 2$ & $30(93.7)$ & $72(97.3)$ & & $22(92.0)$ & $24(96.0)$ & \\
\hline$\geq 3$ & $2(6.3)$ & $2(2.7)$ & & $2(8.0)$ & $1(4.0)$ & \\
\hline
\end{tabular}

Categorical variables are expressed as number and percentage. Continuous variables are indicated as mean \pm SD

ISR indicates in-stent restenosis, PACSS Proposed Peripheral Arterial Calcium Scoring System, PCB paclitaxel-coated balloon, TASC Trans-Atlantic Inter-Society Consensus

"Variables included in the multivariable analysis to estimate propensity score

\section{Clinical outcomes}

Five-year follow-up information was obtained for 19 (76.0\%) PCB patients and in $20(80.0 \%)$ non-PCB patients $(p=1.000)$ after PS matching. At 5 years, the rate of freedom from recurrent restenosis was significantly higher in the PCB group $(65.7 \%)$ than that in the nonPCB group (18.7\%) with a HR of 6.11 and $95 \%$ confidence interval (CI) of 2.57-16.82 $(p<0.001$; Table 4 and Fig. 2), as well as the rate of freedom from TLR $(77.6 \%$ vs. $53.8 \%$; HR: 3.55 ; 95\% CI: $1.21-12.83 ; p=0.020)$. The Rutherford category was improved in both groups similarly after the procedure; whereas the rate of patients with Rutherford category 0 and 1 was significantly higher in the PCB group at 5 years $(p=0.014$; Fig. 3$)$. There was no significant difference between the two groups in terms of all-cause mortality $(16.0 \%$ vs. $12.0 \%$; HR: $1.34 ; 95 \%$ CI: $0.30-6.81 ; p=0.699$ ) (Table 4). No unplanned major amputation was observed in any 
Table 3 Procedural Results

\begin{tabular}{|c|c|c|c|c|c|c|}
\hline \multirow[t]{2}{*}{ Outcomes } & \multicolumn{3}{|c|}{ Overall population } & \multicolumn{3}{|c|}{ Matched population } \\
\hline & PCB $(n=32)$ & Non-PCB $(n=74)$ & $p$ & PCB $(n=25)$ & Non-PCB $(n=25)$ & $p$ \\
\hline Pre-dilatation & $32(100.0)$ & $74(100.0)$ & 1.000 & $25(100.0)$ & $25(100.0)$ & 1.000 \\
\hline Balloon diameter of pre-dilatation, (mm) & $5.27 \pm 0.54$ & $5.31 \pm 0.64$ & 0.729 & $5.22 \pm 0.46$ & $5.44 \pm 0.56$ & 0.137 \\
\hline Balloon/artery ratio of pre-dilatation & $0.94 \pm 0.11$ & $0.96 \pm 0.12$ & 0.307 & $0.93 \pm 0.10$ & $0.99 \pm 0.11$ & 0.052 \\
\hline Balloon pressure of pre-dilatation, (atm) & $11.5 \pm 3.3$ & $11.1 \pm 3.0$ & 0.526 & $11.5 \pm 3.5$ & $10.8 \pm 2.7$ & 0.441 \\
\hline \multicolumn{7}{|l|}{ The detail of PCB } \\
\hline Diameter, (mm) & $5.63 \pm 0.79$ & - & - & $5.60 \pm 0.82$ & - & - \\
\hline Total length, (mm) & $133.8 \pm 52.7$ & - & - & $137.6 \pm 52.1$ & - & - \\
\hline Inflation time, (sec) & $72.2 \pm 32.2$ & - & - & $74.4 \pm 35.8$ & - & - \\
\hline Dilatation pressure, (atm) & $9.1 \pm 3.1$ & - & - & $9.5 \pm 3.4$ & - & - \\
\hline Bail-out stenting & $0(0.0)$ & $20(27.0)$ & $<0.001$ & $0(0.0)$ & $7(28.0)$ & 0.001 \\
\hline \multicolumn{7}{|l|}{ Complications } \\
\hline Slow flow & $3(9.4)$ & $5(6.8)$ & 0.695 & $2(4.0)$ & $1(3.0)$ & 1.000 \\
\hline Distal embolization & $2(6.3)$ & $3(4.1)$ & 0.637 & $2(4.0)$ & $0(0.0)$ & 0.490 \\
\hline Vessel perforation & $0(0.0)$ & $0(0.0)$ & 1.000 & $0(0.0)$ & $0(0.0)$ & 1.000 \\
\hline
\end{tabular}

Categorical variables are expressed as number and percentage. Continuous variables are indicated as mean \pm SD

$P C B$ indicates paclitaxel-coated balloon

patient of the two groups. The Cox proportional hazard multivariate analysis revealed that the use of PCB was independently associated with a lower incidence of recurrent restenosis (HR 0.17, 95\% CI: 0.06-0.41; $p<$ 0.001) (Table 5).

\section{Discussion}

The main findings of the present study are as follows: (1) the recurrent restenosis rate at 5 years after PCB treatment was significantly lower than that after nonPCB treatment; (2) the Cox multivariate analysis revealed that the use of $\mathrm{PCB}$ significantly reduced the incidence of recurrent restenosis; and (3) the cumulative rates of procedural complications, all-cause mortality, and major amputation were not different between the two groups.

Balloon angioplasty can potentially injure the vessel due to overstretching of the wall, denudation of endothelium, rupture of internal elastic lamina, and medial tear leading to the stimulation of smooth muscle cells; therefore, paclitaxel plays an important role in suppressing the stenotic processes (Yahagi et al., 2014). Restenosis and de novo femoropopliteal plaques are different in cellular composition and cell proliferation, the former being highly cellular and comprised primarily of smooth muscle cells (Johnson et al., 1990; Edlin et al., 2009). The suppression of neointimal growth through the antiproliferative effect of paclitaxel led to a consistent lower risk for repeat revascularization and recurrent restenosis (Krankenberg et al., 2015; Kinstner et al., 2016; Ott et al., 2017; Cassese et al., 2018). Thus, the recent guidelines recommend PCB treatment rather than plain balloon angioplasty in ISR lesions, as class IIb (Aboyans et al., 2017).

RCTs reported that the primary patency rates at 6 months after PCB treatment were significantly higher than those after plain balloon angioplasty. However, the 6-month patency after PCB treatment ranged from 58.8 to $84.6 \%$, according to ISR complexity such as lesion length and total occlusion; whereas the 6-month patency in the control group treated by plain balloon angioplasty was reported to range from $41.3 \%$ to $55.3 \%$ and it could

Table 4 Clinical Events after Treatment for In-stent Restenosis at 5 years

\begin{tabular}{|c|c|c|c|c|c|c|}
\hline \multirow[t]{2}{*}{ Variables } & \multicolumn{3}{|c|}{ Overall population } & \multicolumn{3}{|c|}{ Matched population } \\
\hline & PCB $(n=32)$ & Non-PCB $(n=74)$ & $p$ & PCB $(n=25)$ & Non-PCB $(n=25)$ & $p$ \\
\hline Recurrent ISR at 5 years & $8(25.0)$ & $53(71.6)$ & $<0.001$ & $6(24.0)$ & $20(80.0)$ & $<0.001$ \\
\hline All-cause death at 5 years & $4(12.5)$ & $9(12.2)$ & 0.963 & $4(16.0)$ & $3(12.0)$ & 0.699 \\
\hline Target lesion revascularization at 5 years & $5(15.6)$ & $30(40.5)$ & 0.006 & $4(16.0)$ & $11(44.0)$ & 0.020 \\
\hline Unplanned major amputation at 5 years & $0(0.0)$ & $1(1.4)$ & 0.491 & $0(0.0)$ & $0(0.0)$ & 1.000 \\
\hline
\end{tabular}

Categorical variables are expressed as number and percentage, and are calculated based on Kaplan-Meier estimate ISR indicates in-stent restenosis, $P C B$ paclitaxel-coated balloon 

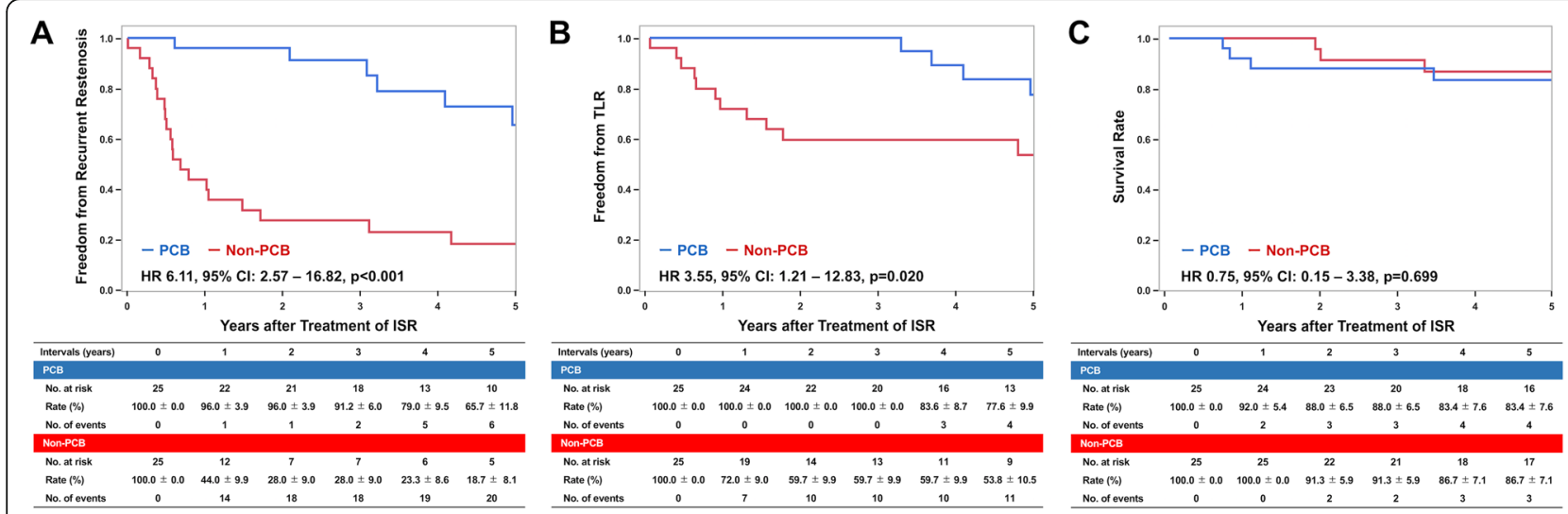

Fig. 2 Clinical Events After EVT within 5 Years. a freedom from recurrent restenosis, b freedom from TLR, and $\mathbf{c}$ survival rate. Cl indicates confidence intervals; HR, hazard ratio; ISR, in-stent restenosis; PCB, paclitaxel-coated balloon; TLR, target lesion revascularization

not differ with the lesion complexity (Krankenberg et al., 2015; Kinstner et al., 2016; Ott et al., 2017; Cassese et al., 2018). The difference between the patency rates might be due to the difficulty associated with vessel preparation before PCB treatment. This study included patients with mainly Tosaka I and II lesions (84.0\%) of relatively short length $(126 \pm 57.4 \mathrm{~mm})$; therefore, the patency rate after PCB treatment was high at $96.0 \%$ within one year, comparing to that in the previous reports (Krankenberg et al., 2015; Kinstner et al., 2016; Ott et al., 2017; Cassese et al., 2018).

In the present study, the rate of Tosaka I and III lesions was significantly higher in the original non- $\mathrm{PCB}$ group before the matching. The possible reason of the discrepancy was the difference of the procedural success and the patency rate according to the severity of ISR patterns. The freedom from recurrent occlusion after plain PTA in Tosaka I ISR was reported to be $84.1 \%$ at 3 years; therefore, we might not tend to use PCB for focal ISR (Tosaka et al., 2012). On the other hand, instent occlusion was generally more difficult to achieve successful pre-dilatation (Grotti et al., 2016) and the bail-out stenting was performed in mainly Tosaka III instent occlusion in the present study. Consequently, the rate of patients with Tosaka III was significantly lower in both the original and matched PCB group. Moreover, the high rate of patients with stent-in-stent treatment might influence of the poor patency rate in the non- $\mathrm{PCB}$ group.

As a previous report demonstrated that the patency after PCB was lower in Tosaka III lesions than in the others (Grotti et al., 2016), it might be better to observe patients carefully after stenting in femoropopliteal lesions and to treat early-staged ISR lesions using PCB.

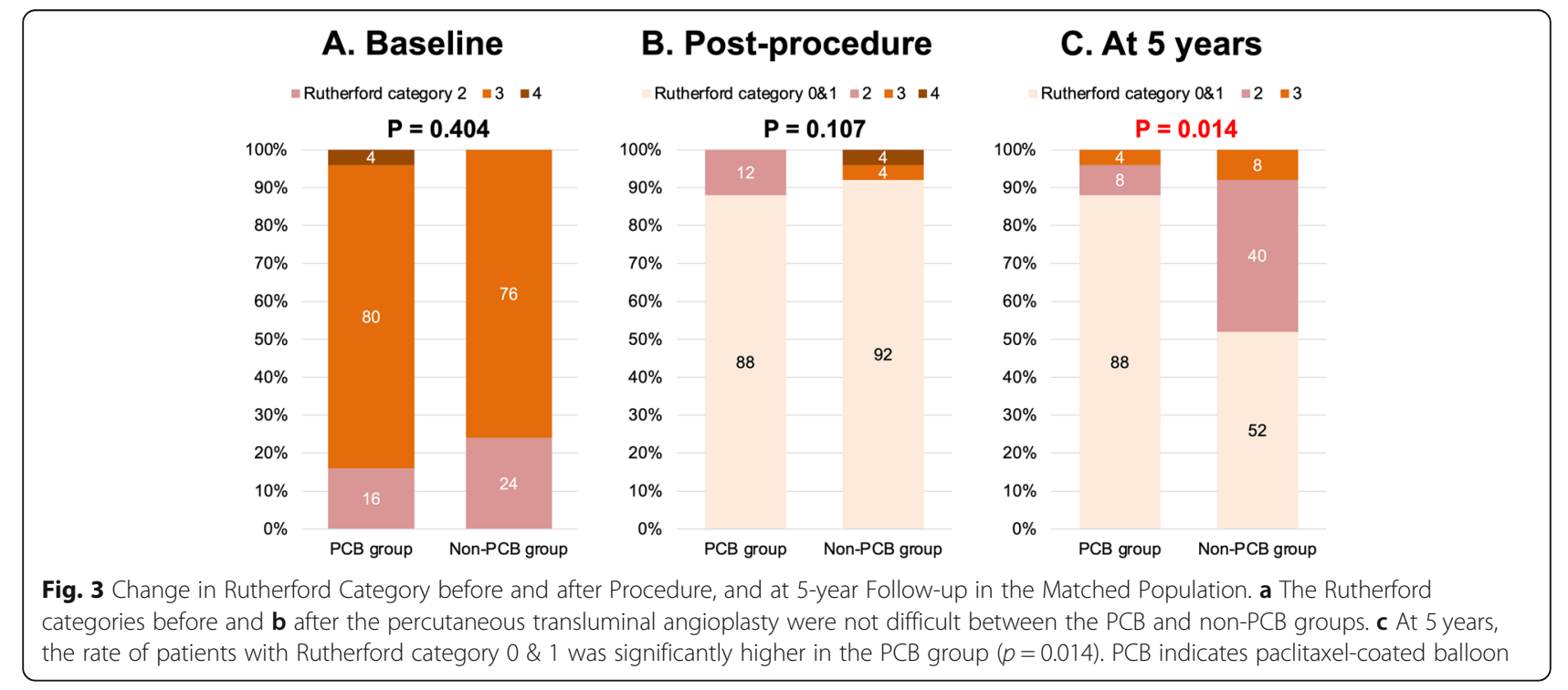


Table 5 Predictors of Recurrent Restenosis within 5 Years after Treatment of In-stent Restenosis in the Matched Population

\begin{tabular}{|c|c|c|c|c|c|c|}
\hline \multirow[t]{2}{*}{ Variables } & \multicolumn{3}{|c|}{ Univariable } & \multicolumn{3}{|c|}{ Multivariable } \\
\hline & HR & $95 \% \mathrm{Cl}$ & $p$ & HR & $95 \% \mathrm{Cl}$ & $p$ \\
\hline Age, (per 1 year) & 1.03 & $0.92-1.03$ & 0.343 & & & \\
\hline Male sex & 1.40 & $0.60-3.55$ & 0.460 & & & \\
\hline Body mass index (per 1.0) & 0.99 & $0.89-1.10$ & 0.835 & & & \\
\hline Dyslipidemia & 0.83 & $0.37-1.80$ & 0.640 & & & \\
\hline Diabetes mellitus & 1.24 & $0.51-2.77$ & 0.618 & & & \\
\hline Current smoker & 1.58 & $0.61-3.64$ & 0.324 & & & \\
\hline Chronic kidney disease & 1.52 & $0.65-4.16$ & 0.351 & & & \\
\hline Hemodialysis & 1.12 & $0.18-3.78$ & 0.881 & & & \\
\hline Use of cilostazol & 1.30 & $0.60-2.91$ & 0.505 & & & \\
\hline Involvement of popliteal lesion & 1.51 & $0.59-3.44$ & 0.370 & & & \\
\hline Reference vessel diameter (per 1.0 mm) & 0.96 & $0.40-2.43$ & 0.925 & & & \\
\hline ISR length (per 10.0 mm) & 1.04 & $0.98-1.10$ & 0.172 & 1.04 & $0.97-1.10$ & 0.251 \\
\hline Tosaka type III (occlusion) & 2.10 & $0.85-4.73$ & 0.102 & 1.39 & $0.55-3.23$ & 0.463 \\
\hline PACSS grade 4 of native lesions & 1.05 & $0.40-3.58$ & 0.933 & & & \\
\hline Tibial runoff $\leq 1$ & 1.65 & $0.72-3.61$ & 0.224 & & & \\
\hline Use of PCB at ISR treatment & 0.16 & $0.06-0.39$ & $<0.001$ & 0.17 & $0.06-0.41$ & $<0.001$ \\
\hline
\end{tabular}

On the other hand, the current meta-analysis demonstrated that debulking devices improved the patency after PTA in patients with complex ISR lesions (Li et al., 2020). Particularly, a combination of laser atherectomy (LA) and PCB was reported to be more effective in reducing the TLR rate within 2 years in Tosaka II and III ISR lesions than LA and plain balloon angioplasty (Kokkinidis et al., 2020; van den Berg et al., 2014). In PCB treatment, lesion modification might be effective in overcoming the complex femoropopliteal ISR lesions.

Liistro et al. demonstrated that PCB reduced the rates of recurrent restenosis and TLR within one year significantly more than plain balloon angioplasty in ISR patients with diabetes and a high prevalence of critical limb ischemia (Liistro et al., 2014); however, they showed that the benefit provided by PCB was not evident at 3 years (Grotti et al., 2016). On the other hand, although the patency after PCB treatment decreased gradually from $96.0 \%$ at 2 years to $65.7 \%$ at 5 years in this study, the patency rate was superior at 5 years to that after plain PTA treatment significantly. The possible reasons of the low rate of this phenomenon, known as "late catch-up," might be due to the difference of patient characteristics. As mentioned above, the PCB group of this study included mainly claudicants and Tosaka II ISR lesions rather than the previous study which had patients with complex characteristics such as diabetes (100.0\%), critical limb ischemia (75.0\%) and Tosaka III lesions (51.0\%) (Grotti et al., 2016; Liistro et al., 2014). These characteristics were associated with poor long- term patency after PCB treatment in patients with de novo femoropopliteal lesions (Laird et al., 2019); therefore, the adverse conditions of PAD patients might influence the patency also in ISR lesions.

The results of a recent meta-analysis aroused concern about an increased risk of death associated with the use of paclitaxel-based devices in lower-limb EVT for PAD (Katsanos et al., 2018). Whereas the latest large-scale RCT comparing paclitaxel-coated and uncoated devices demonstrated that use of coated devices did not increase the mortality of PAD patients within 4 years (Nordanstig et al., 2020). The concern about safety of paclitaxel-coated devices is still inconclusive. Although this study was retrospective and included quite small number of PAD patients, there was not difference in mortality within 5 years between patients treated with and without PCB.

\section{Study limitations}

This study has several limitations. First, it was a singlecenter trial with a small sample size. Therefore, the shortcoming of this study was small number of patients to support meaningful statistics, and especially a valid multivariable analysis. Moreover, this was retrospective; therefore, the follow-up rate was not high. Accordingly, outcomes should be read with extreme cautiousness. Second, because the study duration was 6 years, there was a possibility of bias over time in deciding the EVT procedure. Third, the endpoints were adjudicated by independent observers but not by an external core laboratory. Finally, although we performed PS matching to 
adjust for the differences in baseline clinical and procedural characteristics between the two groups, potential bias could not be excluded in this study, and might have affected the conclusions.

\section{Conclusions}

At 5 years, patients with femoropopliteal ISR lesions treated through PCB showed significantly lower recurrent restenosis and TLR rates than those who underwent non-PCB treatment.

\section{Abbreviations}

BNS: Bare-nitinol stent; Cl: Confidence interval; EVT: Endovascular therapy; HR: Hazard ratio; ISR: In-stent restenosis; LA: Laser atherectomy; PACS S: Proposed Peripheral Arterial Calcium Scoring System; PAD: Peripheral arterial disease; PCB: Paclitaxel-coated balloon; PS: Propensity score; PTA: Percutaneous transluminal angioplasty; TASC: Trans-Atlantic Inter-Society Consensus; TLR: Target lesion revascularization

\section{Acknowledgements}

The authors are very grateful to Kaori Saito, Shizuka Nishimagi, and Saori Ichijo for their support in data collection and analysis of catheterization findings.

\section{Authors' contributions}

The roles of all authors are listed as follows: KH: Conceptualization, Methodology, Data Curation, Writing - Original Draft. AT: Writing, Data Curation - Review \& Editing KS: Supervision. MT: Formal analysis. NI: Supervision. The authors read and approved the final manuscript.

\section{Funding}

This study was not supported by any funding.

\section{Availability of data and materials}

Please contact author for data requests.

\section{Ethics approval and consent to participate}

All procedures performed in studies involving human participants were in accordance with the ethical standards of the institutional (the approval number is 27-33) and with the 1964 Helsinki declaration and its later amendments. Informed consent was obtained from all individual participants included in the study.

\section{Consent for publication}

Consent for publication was obtained for every individual person's data included in the study.

\section{Competing interests}

The authors declare that they have no conflict of interest.

\section{Author details}

'Department of Cardiovascular Medicine, Sendai Kousei Hospital, 4-15 Hirose-cho, Aoba-ku, Sendai, Miyagi 980-0873, Japan. ²Department of Cardiology, Tokyo Saiseikai Central Hospital, Tokyo, Japan. ${ }^{3}$ School of Data Science, Yokohama City University, Kanagawa, Japan.

Received: 3 December 2020 Accepted: 2 January 2021

Published online: 11 January 2021

\section{References}

Aboyans V, Ricco JB, Bartelink MEL, Björck M, Brodmann M, Cohnert T, Collet JP, Czerny M, De Carlo M, Debus S, Espinola-Klein C, Kahan T, Kownator S, Mazzolai L, Naylor AR, Roffi M, Röther J, Sprynger M, Tendera M, Tepe G, Venermo M, Vlachopoulos C, Desormais I, ESC Scientific Document Group (2018) 2017 ESC guidelines on the diagnosis and treatment of peripheral arterial diseases, in collaboration with the European Society for Vascular Surgery (ESVS): document covering atherosclerotic disease of extracranial carotid and vertebral, mesenteric, renal, upper and lower extremity arteries.
Endorsed by the European stroke organization (ESO). The task force for the diagnosis and treatment of peripheral arterial diseases of the European Society of Cardiology (ESC) and of the European Society for Vascular Surgery (ESVS). Eur Heart J 39:763-816

Cassese S, Wolf F, Ingwersen M, Kinstner CM, Fusaro M, Ndrepepa G, Ibrahim T, Ott I, Lammer J, Krankenberg H, Fusaro M (2018) Drug-coated balloon angioplasty for Femoropopliteal in-stent restenosis. Circ Cardiovasc Interv. 11(12):e007055

Edlin RS, Tsai S, Yamanouchi D, Wang C, Liu B, Kent KC (2009) Characterization of primary and restenotic atherosclerotic plaque from the superficial femoral artery: potential role of Smad3 in regulation of SMC proliferation. J Vasc Surg 49:1289-1295

Fanelli F, Cannavale A, Gazzetti M, Lucatelli P, Wlderk A, Cirelli C, d'Adamo A, Salvatori FM (2014) Calcium burden assessment and impact on drug-eluting balloons in peripheral arterial disease. Cardiovasc Intervent Radiol 37:898-907

Gray WA, Keirse K, Soga Y, Benko A, Babaev A, Yokoi Y, Schroeder H, Prem JT, Holden A, Popma J, Jaff MR, Diaz-Cartelle J, Müller-Hülsbeck S (2018) IMPERI AL investigators. A polymer-coated, paclitaxel-eluting stent (Eluvia) versus a polymer-free, paclitaxel-coated stent (Zilver PTX) for endovascular femoropopliteal intervention (IMPERIAL): a randomised, non-inferiority trial. Lancet 392:1541-1551

Grotti S, Liistro F, Angioli P, Ducci K, Falsini G, Porto I, Ricci L, Ventoruzzo G, Turini F, Bellandi G, Bolognese L (2016) Paclitaxel-eluting balloon vs standard angioplasty to reduce restenosis in diabetic patients with in-stent restenosis of the superficial femoral and proximal popliteal arteries: three-year results of the DEBATE-ISR study. J Endovasc Ther 23:52-57

lida O, Takahara M, Soga Y, Suzuki K, Hirano K, Kawasaki D, Shintani Y, Suematsu N, Yamaoka T, Nanto S, Uematsu M (2014) Shared and differential factors influencing restenosis following endovascular therapy between TASC (transAtlantic inter-society consensus) II class a to C and D lesions in the femoropopliteal artery. JACC Cardiovasc Interv. 7:792-798

Johnson DE, Hinohara T, Selmon MR, Braden LJ, Simpson JB (1990) Primary peripheral arterial stenoses and restenoses excised by transluminal atherectomy: a histopathologic study. J Am Coll Cardiol 15:419-425

Katsanos K, Spiliopoulos S, Kitrou P, Krokidis M, Karnabatidis D (2018) Risk of death following application of paclitaxel-coated balloons and stents in the femoropopliteal artery of the leg: a systematic review and meta-analysis of randomized controlled trials. J Am Heart Assoc 7:e011245. https://doi.org/10. 1161/JAHA.118.011245

Kinstner CM, Lammer J, Willfort-Ehringer A, Matzek W, Gschwandtner M, Javor D, Funovics M, Schoder M, Koppensteiner R, Loewe C, Ristl R, Wolf F (2016) Paclitaxel-eluting balloon versus standard balloon angioplasty in in-stent restenosis of the superficial femoral and proximal popliteal artery: 1-year results of the PACUBA trial. JACC Cardiovasc Interv 9:1386-1392

Kokkinidis DG, Behan S, Jawaid O, Hossain P, Giannopoulos S, Singh GD, Laird JR, Valle JA, Waldo SW, Armstrong EJ (2020) Laser atherectomy and drug-coated balloons for the treatment of femoropopliteal in-stent restenosis: 2-year outcomes. Catheter Cardiovasc Interv 95:439-446

Krankenberg $H$, Tübler $T$, Ingwersen $M$, Schlüter $M$, Scheinert $D$, Blessing $E$, Sixt $S$, Kieback A, Beschorner U, Zeller T (2015) Drug-coated balloon versus standard balloon for superficial femoral artery in-stent restenosis: the randomized femoral artery in-stent restenosis (FAIR) trial. Circulation. 132:2230-2236

Laird JA, Schneider PA, Jaff MR, Brodmann M, Zeller T, Metzger DC, Krishnan P, Scheinert D, Micari A, Wang H, Masters M, Tepe G (2019) Long-term clinical effectiveness of a drug-coated balloon for the treatment of Femoropopliteal lesions. Circ Cardiovasc Interv 12:e007702

Li X, Zhou M, Ding Y, Wang Y, Cai L, Shi Z. A systematic review and meta-analysis of the efficacy of debulking devices for in-stent restenosis of the femoropopliteal artery. J Vasc Surg. 2020;72:356-366.e5

Liistro F, Angioli P, Porto I, Ricci L, Ducci K, Grotti S, Falsini G, Ventoruzzo G, Turini F, Bellandi G, Bolognese L (2014) Paclitaxel-eluting balloon vs. standard angioplasty to reduce recurrent restenosis in diabetic patients with in-stent restenosis of the superficial femoral and proximal popliteal arteries: the DEBATE-ISR study. J Endovasc Ther 21:1-8

Nordanstig J, James S, Andersson M, Andersson M, Danielsson P, Gillgren P, Delle M, Engström J, Fransson T, Hamoud M, Hilbertson A, Johansson P, Karlsson L, Kragsterman B, Lindgren $\mathrm{H}$, Ludwigs $\mathrm{K}$, Mellander S, Nyman N, Renlund $\mathrm{H}$, Sigvant B, Skoog P, Starck J, Tegler G, Toivola A, Truedson M, Wahlgren CM, Wallinder J, Öjersjö A, Falkenberg M. Mortality with Paclitaxel-Coated Devices in Peripheral Artery Disease. N Engl J Med. 2020 9. doi: https://doi.org/10. 1056/NEJMoa2005206. Epub ahead of print. PMID: 33296560 
Norgren L, Hiatt WR, Dormandy JA, Nehler MR, Harris KA, Fowkes FG; TASC II Working Group, Bell K, Caporusso J, Durand-Zaleski I, Komori K, Lammer J, Liapis C, Novo S, Razavi M, Robbs J, Schaper N, Shigematsu H, Sapoval M, White C, White J, Clement D, Creager M, Jaff M, Mohler E 3rd, Rutherford RB, Sheehan P, Sillesen H, Rosenfield K. Inter-Society Consensus for the Management of Peripheral Arterial Disease (TASC II). Eur J Vasc Endovasc Surg. 2007;33 Suppl 1:S1-75. https://doi.org/10.1016/j.ejvs.2006.09.024.

Ott I, Cassese S, Groha P, Steppich B, Voll F, Hadamitzky M, Ibrahim T, Kufner S, Dewitz K, Wittmann T, Kasel AM, Laugwitz KL, Schunkert H, Kastrati A, Fusaro M (2017) ISAR PEBIS (paclitaxel-eluting balloon versus conventional balloon angioplasty for in-stent restenosis of superficial femoral artery): a randomized trial. J Am Heart Assoc 6:e006321

Rocha-Singh KJ, Zeller T, Jaff MR (2014) Peripheral arterial calcification: prevalence, mechanism, detection, and clinical implications. Catheter Cardiovasc Interv 83:E212-E220

Schillinger M, Sabeti S, Loewe C, Dick P, Amighi J, Mlekusch W, Schlager O, Cejna M, Lammer J, Minar E (2006) Balloon angioplasty versus implantation of nitinol stents in the superficial femoral artery. N Engl J Med 354:1879-1888

Soga Y, lida O, Hirano K, Yokoi H, Nanto S, Nobuyoshi M (2010) Mid-term clinical outcome and predictors of vessel patency after femoropopliteal stenting with self-expandable nitinol stent. J Vasc Surg 52:608-615

Tosaka A, Soga Y, lida O, Ishihara T, Hirano K, Suzuki K, Yokoi H, Nanto S, Nobuyoshi M (2012) Classification and clinical impact of restenosis after femoropopliteal stenting. J Am Coll Cardiol 59:16-23

van den Berg JC, Pedrotti M, Canevascini R, Chimchila Chevili S, Giovannacci L, Rosso R (2014) In-stent restenosis: mid-term results of debulking using excimer laser and drug-eluting balloons: sustained benefit? J Invasive Cardiol 26:333-337

Yahagi K, Otsuka F, Sakakura K, Sanchez OD, Kutys R, Ladich E, Kolodgie FD, Virmani R, Joner M (2014) Pathophysiology of superficial femoral artery instent restenosis. J Cardiovasc Surg 55:307-323

\section{Publisher's Note}

Springer Nature remains neutral with regard to jurisdictional claims in published maps and institutional affiliations.

\section{Submit your manuscript to a SpringerOpen ${ }^{\circ}$ journal and benefit from:}

- Convenient online submission

- Rigorous peer review

- Open access: articles freely available online

High visibility within the field

- Retaining the copyright to your article

Submit your next manuscript at $\boldsymbol{\nabla}$ springeropen.com 